\title{
Em busca de um dialogo entre Plano Nacional de Educação (PNE), Formação de professores e multi/interculturalismo
}

Aline Cleide Batista*

Paulo Melgaço da Silva Junior**

Ana Canen ***

\section{Resumo}

O presenteartigo se propõe a analisar como as propostas multi/interculturais estão refletidas no texto do PNE 2011-2020. Argumentamos que uma educação multi/intercultural pode contribuir para a construção de uma educação que valorize e reconheça as múltiplas culturas presentes no cotidiano e, sobretudo, promover uma interrelação entre as diferentes identidades culturais. Defendemos a relevância desta análise, apoiados em argumentos a partir de autores que nos mostram a centralidade da cultura em nossos tempos. Com isso, destacamos como se dá a expansão dos determinantes associados à cultura a partir da segunda metade do século XX, e como ela tem assumido uma posição central na vida dos sujeitos, em processos globais de formação e mudança. Por isso, torna-se de fundamental importância refletir como o PNE (Plano Nacional de Educação) está incorporando as questões propostas pelo multi/interculturalismo, principalmente aquelas relativas à formação de professores/as. Concluímos, reconhecendo queéessencial que oscursos de formação docente inicial e continuada desenvolvam as discussões sobre o multi/interculturalismo, no horizonte de uma educação crítica, para a superação de desigualdades, exclusões sociais, preconceitos e modelos hegemônicos monoculturais de educação.

Palavras-chave: PNE. Formação de professores. Multi/interculturalismo

\section{In search of a dialogue between the Brazilian National Plan of Education (PNE), teacher education and multi/interculturalism}

\section{Abstract}

The present paper intends to anlayse how the multi/intercultural proposals are reflected in the National Educational Plan (PNE) 2011-2020. We argue that the

* Doutoranda em Educação - PPGE/UFRJ. E-mail: alinecleide@yahoo.com.br

** Doutorando em Educação - PPGE/UFRJ. E-mail: pmelgaco@uol.com.br

*** Professora e pesquisadora do PPGE//FE/UFRJ, pesquisadora do PROEDES/UFRJ, Rio de Janeiro, RJ e pesquisadora do CNPq. E-mail: acanen@globo.com 
multi/intercultural education can contribute to the construction of an educational process that values and recognises the multiple cultures that circulate in everyday school life, particularly promoting a positive interrelationship among the different cultural identities. We defend the relevance of the analysis, particularly drawing on arguments from authors that posit the centrality of a cultural approach to the contemporary life. By doing that, we highlight how the expansion of the concept of culture and of the determinants associated to it takes place from the middle of the $20^{\text {th }}$ century onwards, discussing how it has been gaining the forefront in individuals' lives, within the global process of formation and change. In that vein, we contend it is crucial to reflect how the PNE has incorporated such multi/ intercultural proposals in teacher education. We conclude, by recognising it is central that teacher education courses develop multi/intercultural discussions, so as to develop a critical education that challenges inequality, social inclusion, prejudices and an hegemonic monocultural model of education.

Keywords: PNE. Teacher education. Multi/interculturalism

\section{En la búsqueda de un diálogo entre el Plan Nacional de Brasil de la Educación (PNE), la formación del profesorado y multi / interculturalidad}

\section{Resumen}

El presente artículo se propone analizar como las propuestas multi/interculturales están reflejadas en el texto del Plan Nacional de Educación (PNE) 2011-2020. Argumentamos que una educación multi/intercultural puede contribuir para la construcción de una educación que valorice y reconozca las múltiples culturas presentes en el cotidiano y sobre todo promoviendo una interrelación entre las diferentes identidades culturales. Defendemos la relevancia de este análisis apoyados en autores que nos muestram la centralidad de la cultura en nuestros tiempos. Con esto, destacando como se da la expansión de todo lo que está asociado a cultura a partir de la segunda mitad del siglo XX y como ésta ha asumido una posición central en la vida de los sujetos en el proceso global de formación y cambio. Por eso, se torna de fundamental importancia reflexionar sobre como el PNE está incorporando las cuestiones propuestas por el multi/interculturalismo, principalmente en las cuestiones relativas a la formación de profesores(as). Concluimos reconociendo que es esencial que los cursos de formación inicial y continua desarrollen las discusiones sobre el multi/interculturalismo con el objetivo de desarrollar una educación crítica para la superación de la desigualdad y la exclusión social, del preconcepto y del modelo hegemónico y monocultural de educación.

Palabras clave: Plano Nacional de Educación. Formación de professores. Multi/ interculturalismo 


\section{Introdução}

0 objetivo central deste texto é refletir em que medida as propostas multi/ interculturais estão refletidas no texto do Plano Nacional de Educação - PNE (BRASIL, 2011), em tramitação no Congresso Nacional para entrar em vigor nos próximos 10 anos. Defendemos a relevância desta análise apoiados em autores, tais como Hall (1997) que nos mostra a centralidade da cultura e de seus impactos na formação das identidades dos sujeitos, portanto, assumindo papel de destaque na discussão de processos educacionais e do PNE. A partir do exposto, argumentamos que uma educação multi/intercultural pode contribuir para a construção de uma educação que valorize e reconheça as múltiplas culturas presentes no cotidiano e, sobretudo, promovendo uma interrelação entre as diferentes identidades culturais. É importante destacar que entendemos o multi/interculturalismo como uma proposta que desafia congelamentos identitários e que busca responder às questões propostas pela diversidade cultural. Multiculturalismo é aqui assumido como corpo teórico e político de conhecimentos, que privilegia o múltiplo, o plural, as identidades marginalizadas e silenciadas e que busca formas alternativas para sua incorporação no cotidiano educacional (CANEN, 2008). Destacamos que essa vertente não pode ser separada das relações de poder que perpassam os espaços educacionais pelos quais circulam as identidades culturais (SILVA, 2001), sendo interessante perceber formas pelas quais as respostas à diversidade cultural podem assumir caráter mais crítico, desafiando discriminações, preconceitos e processos discursivos que congelam relações desiguais.

Por outro lado, as discussões sobre a formação dos professores cresceram significativamente nos últimos anos, associadas à busca por uma melhor qualidade na educação. Neste sentido, a atuação dos professores no contexto educativo não se esgota no simples conhecimento, ou mesmo na mera transmissão de conteúdos. Outro fator preponderante na prática pedagógica se revela quando lidamos diretamente com a construção do conhecimento, o que torna necessário "definir a especificidade da ação docente como ação formativa intencional e sistematizada, para não banalizá-la com base na constatação verdadeira, porém parcial, de que todas as relações sociais e produtivas são pedagógicas, com o que todos são professores (...)". (KUENZER, 1999, p. 7).

A educação nacional brasileira vivencia um momento decisório importante na organização da educação enquanto sistema educacional, no que diz respeito à definição de políticas que orientarão seu rumo, por um período de dez anos. Assim, torna-se de fundamental importância refletir em que medida e de que forma o PNE vem incorporando as questões propostas pelo multi/interculturalismo.

0 presente artigo está estruturado da seguinte maneira: no primeiro momento apresentamos uma breve reflexão sobre a perspectiva multicultural, para, a seguir, analisarmos o PNE à luz da argumentação proposta. 


\section{Multi/ Interculturalismo na Formação de Professores: algumas reflexões}

Existe uma grande polissemia em relação ao termo multiculturalismo. Candau (2009) destaca que expressões como multiculturalismo conservador, liberal, celebratório, crítico, emancipador e revolucionário podem ser encontradas na produção sobre o tema e se multiplicam continuamente. No multiculturalismo folclórico as culturas são interpretadas em seus aspectos exóticos, ou seja, trata-se de impregnar o currículo com festas, ritos, formas de pensar e agir de diversos povos, raças, religiões e classes. 0 multiculturalismo crítico, por sua vez, propõe interrogar, questionar, historicizar a cultura dominante, colocando questões que revelem a (s) história (s) que produziram as presentes identidades. No entanto, as perspectivas do multiculturalismo interativo ou multiculturalismo pós-colonial propõem a interrelação entre os diversos grupos socioculturais, reconhecendo que as identidades não são puras e que existe a necessidade de reconhecer a diferença dentro das diferenças. Reconhecem que vivemos em processos de hibridização cultural, onde culturas se relacionam, identidades se cruzam e estão sempre em movimento, mostrando que as relações sociais não são pacíficas, idealizadas ou romantizadas e sim construídas na história, atravessadas por relações de poder, hierarquias socialmente construídas e marcadas pela discriminação (CANEN, SANTOS, 2009; CANEN, CANEN, 2008).

Nesse sentido, apontamos para a necessidade da desnaturalização da cultura escolar dominantenos sistemas de ensino, bem como para a relevância de incorporar a dimensão cultural na prática docente nos cursos de formação inicial e continuada de professores, conjugando, como propõem Candau e Arnhorn (2002), a cultura de referência dos alunos com a cultura escolar. Para tanto, consideramos de suma importância que a formação inicial e continuada analise a prática docente em conjunto com as questões sociais, políticas, econômicas e culturais. Isso porque a compreensão e o desafio a relações de poder desiguais e aos processos de exploração e de discriminações com relação a identidades marginalizadas é fundamental, de modo que o trabalho dos professores esteja voltado para a superação da desigualdade e da exclusão social.

Desse modo, ao se pretender desenvolver uma prática pedagógica crítica, não basta a celebração da pluralidade, ou a tolerância da diferença. É importante que haja um investimento de esforços na busca da superação das condições que perpetuam as desigualdades e a exclusão, desenvolvendo-se, dentro de uma linguagem da vida pública, comunidades emancipatórias e comprometimento individual e social. Isto porque as escolas e outros locais sociais e culturais raramente estão completamente subjugados pelo processo hegemônico, pois neles também há luta e resistência. (MCLAREN, 1997).

Nesse sentido apontamos para a necessidade de uma formação de professores para atuarem em sociedades multiculturais, constituídas na pluralidade, na 
multiplicidade e nas diferenças. Observamos que estas questões têm sido ressaltadas na literatura nacional e internacional, por autores tais como Candau (1997, 2008, 2009), Canen (2002, 2007, 2008, 2009); Canen e Canen (2005, 2008); M cLaren (2000) e Moreira e Candau (2008), além de literatura que tem questionado o racismo e se tem se dedicado a propostas de formação docente que o supere, como, por exemplo, Assis e Canen (2004), Oliveira (2010), Oliveira e Candau (2011) e Siss (2003).

Coerente com essa abordagem, Canen e Xavier (2005) defendem que o perfil do professor como profissional reflexivo, que assume uma prática enquanto processo de ação/reflexão/ação, pode articular-se às posturas multiculturais, promovendo a formação do professor pesquisador multiculturalmente comprometido. Tal perspectiva representa uma via pela qual as conexões entre 0 universo microssocial da sala de aula e a realidade cultural e social mais ampla possa se efetuar, possibilitando desafiar discursos que congelam identidades e reforçam preconceitos.

Para tanto, a educação multicultural irá focalizar, além da diversidade cultural e identitária, os processos discursivos nos quais as identidades e culturas são formadas. Portando, a visão multicultural não se limita a constatar a pluralidade de identidades e os preconceitos construídos nas relações de poder entre as mesmas. Trata-se de compreender a construção de significados que, dentro de um grupo, ganham força e se hegemonizam temporariamente, buscando-se analisar criticamente os discursos que fabricam essas identidades e essas diferenças e procurando, ao mesmo tempo, interpretar a identidade como uma construção, ela própria múltipla e plural. Assim, a própria identidade, compreendida como provisória e híbrida, é objeto de análise do multiculturalismo. Da mesma forma, o hibridismo ou hibridização é conceito central dessa perspectiva multicultural: "a construção da identidade implica que as múltiplas camadas que a perfazem a tornem híbrida, isto é, formada na multiplicidade de marcas, construídas nos choques e entrechoques culturais". (CANEN, 2007, p. 95).

\section{Análise do projeto de lei do PNE 2011 - 2020}

A partir do exposto, a análise do PNE torna- se relevante à medida que buscamos detectar sensibilidades que perfazem a perspectiva multicultural. O PNE, Plano Nacional de Educação, é apresentado como um texto do Projeto de Lei 8035/10 de autoria do Executivo, em tramitação na Câmara Federal, que estabelece os rumos da educação brasileira (BRASIL, 2011). Este documento a ser aprovado para vigência 2011-2020 é composto por 12 artigos e um anexo com 20 metas para a Educação.

Sabemos que a educação brasileira é marcada por sérios desafios que questionam a possibilidade de pleitearmos uma educação de qualidade. Não podemos negar os avanços que o sistema educacional tem adquirido ao longo dos anos: a quase massificação do acesso à escola pública gratuita, o crescente número de pessoas cursando nível superior, os avanços na produção e na pesquisa no trato das questões 
educacionais, a "democratização" na gestão, dentre outros. Porém, temos que lamentar os resultados quanto à qualidade do processo de ensino-aprendizagem. M uito se tem feito na tentativa de acompanhar e controlar essa qualidade, como, por exemplo, os processos avaliativos de larga escala (por exemplo, Enem, Ideb, Provinha Brasil...), que têm buscado analisar variáveis que influenciam a aprendizagem, com vistas a servirem de bases para planos e propostas de melhoria. Os resultados revelam que, lado a lado com um crescimento e uma melhora do acesso à educação, a média nacional em termos de aprendizagem efetiva ainda deixa a desejar, com médias de aprovação baixas e, ainda, indicando profundas disparidades entre escolas da rede, escolas particulares, e abalando a credibilidade nas atuais medidas preventivas/ reativas que constituem os muitos programas de ação na educação.

No momento em que se define o rumo da educação para os próximos dez anos, é tempo de refletirmos e de analisarmos os avanços, recuos e permanências presentes nas propostas e documentos. Em termos de avanços, quando se pensa em termos da perspectiva multicultural que informa o presente artigo, é importante reconhecermos o "avanço" no processo no qual se delineia este novo PNE, na medida em que constitui processo coletivamente construído, a partir do diálogo entre vozes plurais que perfazem a educação nacional. De fato, observa- se que o documento passa por etapas de construção com trocas de opiniões e pareceres entre diferentes instâncias, na tentativa de se fazer um documento que pudesse expressar os anseios e necessidades frente às diversas realidades plurais que constituem o Brasil.

0 documento elaborado na Conferencia Nacional da Educação - Conae (CONFERÊNCIA NACIONALDE EDUCAÇÃO, 2010), que constituiu a base preliminar para a construção do PNE, expressa essa tentativa de elaboração de um documento quetivesse por parâmetro as vozes do campo educacional, ou seja, possuía o objetivo de conhecer as aspirações e desejos de diferentes grupos de profissionais da educação brasileira. Naquela ocasião, o documento foi estruturado/organizado em seis eixos temáticos, quais sejam: I- Papel do Estado na Garantia do Direito à Educação de Qualidade: Organização e Regulação da Educação Nacional; II - Qualidade da Educação, Gestão Democrática e Avaliação; III - Democratização do Acesso, Permanência e Sucesso Escolar; IV - Formação eValorização dos Trabalhadoresem Educação; V- Financiamento da Educação eControle Social; Vl - Justiça Social, Educação e Trabalho: Inclusão, Diversidade e Igualdade.

0 desdobramento desses eixos aparece no PNE, nesta primeira versão, representado, sinteticamente, em doze artigos que norteiam e orientam as 20 metas, previstas no anexo do documento, com estratégias a serem desenvolvidas no intuito de se alcançar as respectivas metas.

Nesses doze artigos, podemos identificar algumas preocupações com a diversidade, conforme aparecem nos seguintes excertos: no art. 2ํㅡ - difusão dos princípios da 
equidade, do respeito à diversidade e a gestão democrática da educação; no parágrafo 3ㅇdo artigo 70, § 3ㅇ A educação escolar indígena deverá ser implementada por meio de regime de colaboração específico que considere os territórios étnico-educacionais e de estratégias que levem em conta as especificidades socioculturais e linguísticas de cada comunidade, promovendo a consulta prévia e informada a essas comunidades; no artigo 8으, que dispõe sobre a elaboração de planos de educação nas esferas do estado e dos municípios, onde os parágrafos $1^{\circ}$ e $2^{\circ}$ apontam para 0 atendimento à diversidade, especificadas nas particularidades da educação do campo, aos quilombolas e ao atendimento às necessidades especiais, assim escrito no documento: $\S$ 10 Os entes federados deverão estabelecer em seus respectivos planos de educação metas que considerem as necessidades específicas das populações do campo e de áreas remanescentes de quilombos, garantindo equidade educacional. $§ 2^{\circ}$ Os entes federados deverão estabelecer em seus respectivos planos de educação metas que garantam 0 atendimento às necessidades educacionais específicas da educação especial, assegurando um sistema educacional inclusivo em todos os níveis, etapas e modalidades.

No que se refere à formação continuada dos professores, no entanto, observase que os doze artigos do atual plano não apresentam nenhuma proposta ou apontamento quanto a proposições e definições de ações a serem desenvolvidas nesse sentido, o que parece indicar a omissão de uma discussão ímpar e imprescindível quando se pensa em avanço na educação, em termos de preparação multicultural de docentes. De fato, o único momento em que essa discussão aparece

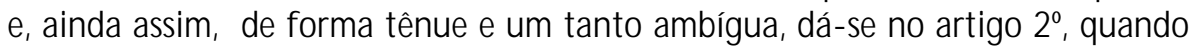
o PNE apresenta, como diretrizes para a formação docente, os seguintes itens: V formação para o trabalho; IX - valorização dos profissionais da educação. Quanto à formação para o trabalho, parece perpassar a predominância da idéia vinculada à educação profissional, em moldes um tanto semelhantes àqueles presentes na Lei n. 5692/71 (BRASIL, 1971). Isto no sentido da grande ênfase ao ensino tecnológico e profissionalizante, que foi alvo de críticas e de lutas para sua superação.

No que diz respeito à valorização dos profissionais da educação, percebemos uma preocupação com a carreira desses profissionais, podendo caracterizar- se como um avanço que expressa resultado de muitas lutas políticas dos mesmos. No entanto, no decorrer do documento, observamos que essa valorização parece estar centrada na certificação em níveis de pós- graduação lato e stricto sensu. Tais certificações são encaradas como possibilitadoras do crescimento e do avanço na carreira, sendo claramente atreladas ao melhoramento dos salários - as ditas promoções. Nesse ponto, parece muito preocupante perceber que a valorização profissional, longe de enfatizar processos de crescimento ef etivo, com relação a atuações em contextos de diversidade cultural e a incrementos salariais efetivos, volta-se, ao contrário, a perspectivas de "bonificações" adquiridas por certificações em cursos. Podemos observar, também, uma ausência de preocupação explícita de que os mesmos se 
organizem de modo a possibilitar uma formação continuada efetivamente de qualidade, podendo tal perspectiva vir a eventualmente resultar em uma possível futura mercantilização de cursos de mestrado e doutorado. Destacamos que a estratégia referente a esta meta está contida no seguinte artigo: 14.4 Expandir a of erta de cursos de pós- graduação stricto sensu utilizando metodologias, recursos e tecnologias de educação a distância, inclusive por meio do Sistema Universidade Aberta do Brasil - UAB. (BRASIL, 2011).

Entretanto, ressaltamos que uma outra perspectiva parecia ser apontada no documento da Conferência Nacional de Educação - Conae (CONFERÊNCIA NACIONAL DE EDUCAÇÃO, 2010), deixando clara a preocupação com a qualidade da formação de professores, conforme se observa nos extratos a seguir:

\begin{abstract}
A formação ea valorização dos/das profissionais do magistério devem contemplar aspectos estruturais, particularmente, e superar as soluções emergenciais, tais como: cursos de graduação (formação inicial) a distância; cursos de duração reduzida; contratação de profissionais liberais como docentes; aproveitamento de estudantes de licenciatura como docentes; e uso complementar de telessalas. E extinguir, ainda, todas as políticas aligeiradas de formação por parte de "empresas", por apresentarem conteúdos desvinculados dos interesses da educação pública, bem como superar políticas de formação que têm como diretriz o parâmetro operacional do mercado e visam a um novo tecnicismo, separando concepção e execução na prática educacional. (CONFERÊNCIA NACIONAL DE EDUCAÇÃO, 2010).
\end{abstract}

Expostas essas considerações, passamos a fazer um exercício de tentar localizar, nas metas anexas ao documento, questões que tratam da diversidade cultural, da formação continuada de professores e da relação entre estas. Essa ação teve objetivo tentar perceber em que trechos há uma possível preocupação com a diversidade cultural, com a formação continuada e onde essas preocupações possam, porventura, aparecer, de forma concomitante. Destacamos, nos extratos a seguir, a mesma tendência detectada de interpretação da diversidade cultural em termos essencializadores de identidades coletivas e de uma aparente separação da questão da formação inicial e continuada de professores, destas preocupações.

Por exemplo, a meta 1 expressa que se deseja “Universalizar, até 2016, 0 atendimento escolar da população de 4 e 5 anos, e ampliar, até 2020, a of erta de educação infantil de forma a atender a $50 \%$ da população de até 3 anos", sendo que o item 1.5 desta meta, refere-se a "Fomentar a formação inicial e continuada de profissionais do magistério para a educação infantil" (BRASIL, 2011). Nesse caso, a questão da ampliação da oferta 
e da articulação da formação de professores à mesma dão-se em função de aspectos quantitativos, sem que se apresente uma clara articulação da proposta com a diversidade cultural das identidades infantis que se apresentam.

Da mesma forma, as metas 2, 4 e 7 expressam a intenção de crescimento quantitativo de oferta de acesso à educação pública, sem dúvida passo relevante na direção da educação equitativa. Porém, em termos do foco sobre a diversidade cultural, mais uma vez, parece haver ora um silenciamento, ora uma redução da mesma à educação do campo e/ou à educação especial, de modo essencializador e pouco sensível à dimensão multicultural crítica ou pós-colonial de compreensão da importância do desafio a preconceitos e de compreensão do caráter híbrido da construção desta diversidade, conforme argumentado na primeira parte deste artigo. Alguns extratos podem ser ilustrativos, neste ponto:

Meta 2: Universalizar o ensino fundamental de nove anos para toda população de 6 a 14 anos. Diversidade e Formação: 2.5) Manter programa nacional de reestruturação e aquisição de equipamentos para escolas do campo, bem como de produção de material didático e de formação de professores para a educação do campo, com especial atenção às classes multisseriadas. Meta 4: Universalizar, para a população de 4 a 17 anos, 0 atendimento escolar aos estudantes com deficiência, transtornos globais do desenvolvimento e altas habilidades ou superdotação na rede regular de ensino. 4.2) Implantar salas de recursos multifuncionais e fomentar a formação continuada de professores para 0 atendimento educacional especializado complementar, nas escolas urbanas e rurais. Meta 7: Atingir as seguintes médias nacionais para o IDEB: 7.1) Formalizar e executar os planos de ações articuladas dando cumprimento às metas de qualidade estabelecidas para a educação básica pública e às estratégias de apoio técnico e financeiro voltadas à melhoria da gestão educacional, à formação de professores e profissionais de serviços e apoio escolar, ao desenvolvimento de recursos pedagógicos e à melhoria e expansão da infra-estrutura física da rede escolar.7.13) Informatizar a gestão das escolas e das secretarias de educação dos Estados, do Distrito Federal e dos Municípios, bem como manter programa nacional de formação inicial e continuada para o pessoal técnico das secretarias de educação. (BRASIL, 2011).

Em outros pontos, no entanto, há de se registrar a preocupação com a desigualdade entre negros e não negros e a intenção de trabalhar na direção da educação para a diversidade que também desafie desigualdades, aproximando-se mais da perspectiva multicultural crítica, conforme se observa na meta a seguir destacada: 
Meta 8: Elevar a escolaridade média da população de 18 a 24 anos de modo a alcançar mínimo de 12 anos de estudo para as populações do campo, da região de menor escolaridade no país e dos $25 \%$ mais pobres, bem como igualar a escolaridade média entre negros e não negros, com vistas à redução da desigualdade educacional. (BRASIL, 2011).

Entretanto, é importante salientar que, no texto do PNE, ainda é possível detectar uma dissociação no que se refere ao currículo escolar e de formação de professores, entre concepções curriculares, metodológicas e avaliativas e aquelas referentes à valorização da diversidade cultural. Nesse sentido, a ideia parece ser a de que a diversidade cultural apresenta- se como horizonte sem que, no entanto, seja articulada aos conteúdos e programas de formação, como se percebe a seguir, nas alíneas ligadas às metas 10 e 12 relativas à dimensão pedagógica da formação continuada de professores:

10.5) Fomentar a produção de material didático, 0 desenvolvimento de currículos e metodologias específicas para avaliação, formação continuada de docentes das redes públicas que atuam na educação de jovens e adultos integrada à educação profissional.12.4) Fomentar a oferta de educação superior pública e gratuita prioritariamente para a formação de professores para a educação básica, sobretudo nas áreas de ciências e matemática, bem como para atender o déficit de profissionais em áreas específicas. 13.4) Induzir a melhoria da qualidade dos cursos de pedagogia e licenciaturas, por meio da aplicação de instrumento próprio de avaliação aprovado pela CONAE, de modo a permitir aos graduandos a aquisição das competências necessárias a conduzir o processo de aprendizagem de seus futuros alunos, combinando formação geral e prática didática. 15.1) Atuar conjuntamente, com base em plano estratégico que apresente diagnóstico das necessidades de formação de profissionais do magistério e da capacidade de atendimento por parte de instituições públicas e comunitárias de educação superior existentes nos Estados, Municípios e Distrito Federal, e defina obrigações recíprocas entre os partícipes.15.3) Ampliar programa permanente de iniciação à docência a estudantes matriculados em cursos de licenciatura, a fim de incentivar a formação de profissionais do magistério para atuar na educação básica pública.15.4) Consolidar plataforma eletrônica para organizar a oferta e as matrículas em cursos de formação inicial e continuada de professores, bem como para divulgação e atualização dos currículos eletrônicos dos docentes.15.7) Promover a reforma curricular dos cursos de licenciatura de forma a assegurar 0 foco no aprendizado do estudante, dividindo a carga horária 
em formação geral, formação na área do saber e didática específica.15.8) Induzir, por meio das funções de avaliação, regulação e supervisão da educação superior, a plena implementação das respectivas diretrizes curriculares.15.9) Valorizar o estágio nos cursos de licenciatura, visando um trabalho sistemático de conexão entre a formação acadêmica dos graduandos e as demandas da rede pública de educação básica.15.10) Implementar cursos e programas especiais para assegurar formação específica em sua área de atuação aos docentes com formação de nível médio na modalidade normal, não-licenciados ou licenciados em área diversa da de atuação docente, em efetivo exercício. (BRASIL, 2011).

Nesse sentido, observa- se que o currículo de formação docente para a diversidade cultural passa a ser enfatizado apenas no caso de professores que irão atuar com populações do campo, comunidades quilombolas e povos indígenas, em detrimento de uma visão que articule tal currículo e suas dimensões pedagógicas ao olhar multicultural (CANEN E SANTOS, 2009), como se verifica a seguir.

15.6) Implementar programas específicos para formação de professores para as populações do campo, comunidades quilombolas e povos indígenas. (BRASIL, 2011).

Há que se destacar que outros incisos constantes das metas que se referem à formação de professores referem-se a aspectos institucionais e políticos dessa formação, sem destaque à importância da sensibilidade às identidades culturais plurais nas mesmas, como ilustram os extratos a seguir.

16.1) Realizar, em regime de colaboração, o planejamento estratégico para dimensionamento da demanda por formação continuada e fomentar a respectiva oferta por parte das instituições públicas de educação superior, de forma orgânica e articulada às políticas de formação dos Estados, do Distrito Federal e dos Municípios.16.2) Consolidar sistema nacional de formação de professores, definindo diretrizes nacionais, áreas prioritárias, instituições formadoras e processos de certificação dos cursos.16.3) Expandir programa de composição de acervo de livros didáticos, paradidáticos, de literatura e dicionários, sem prejuízo de outros, a ser disponibilizado para os professores das escolas da rede pública de educação básica.16.4) Ampliar e consolidar portal eletrônico para subsidiar o professor na preparação de aulas, disponibilizando gratuitamente roteiros didáticos e material suplementar.16.5) Prever, nos planos de carreira dos profissionais da educação dos Estados, do Distrito Federal e dos M unicípios, licenças para qualificação profissional 
em nível de pós-graduação stricto sensu.18.2) Instituir programa de acompanhamento do professor iniciante, supervisionado por profissional do magistério com experiência de ensino, a fim de fundamentar, com base em avaliação documentada, a decisão pela efetivação ou não- efetivação do professor ao final do estágio probatório.18.4) Fomentar a oferta de cursos técnicos de nível médio destinados à formação de funcionários de escola para as áreas de administração escolar, multimeios e manutenção da infra-estrutura escolar, inclusive para alimentação escolar, sem prejuízo de outras.18.5) Implantar, no prazo de um ano de vigência desta Lei, política nacional de formação continuada para funcionários de escola, construída em regime de colaboração com os sistemas de ensino. (BRASIL, 2011).

Observa-se que, em geral, a preocupação com a diversidade volta- se preferencialmente para as questões do campo e dos povos indígenas ou, por outro lado, a prioridade às questões estruturais de organização de calendário escolar - de tempo e de acesso a escola - sem sua articulação à diversidade propriamente dita. Trata-se, assim, de uma formação de professores voltada ora para atender a demandas curriculares universalizantes, ora para atender a demandas específicas daquelas identidades coletivas específicas destacadas. Nesse aspecto, observamos que, diante de um cenário no qual o preconceito contra o diferente é cada vez mais exacerbado, violento e agressivo, preparar professores para a diversidade cultural é, mais do que nunca, uma necessidade premente da qual nenhum de nós deve esquivar- se. (CANEN, 2009).

Também, observa- se, no contexto do documento analisado, que o discurso acerca da formação dos professores para Educação de J ovens e Adultos é semelhante àquele apresentado na meta que trata da potencialização do ensino médio. É interessante observar que, na meta que trata da integração Educação de Jovens e Adultos e Educação Profissional, não aparece nenhuma discussão acerca da diversidade. É como se todos os jovens e adultos tivessem as mesmas necessidades e características, uniformemente. De fato, a única referência à formação em serviço aparece no item 15.5, de forma vaga e como uma decorrência de uma possível política nacional de formação de professores. Portanto a formação continuada em serviço, priorizando a relação teoria prática e a reflexão com os saberes da experiência, conforme havia sido configurada em documentos anteriores, neste PNE não é apresentada como estratégia de formação. A grande proposta de formação para professores, neste documento, está vinculada a cursos acadêmicos com certificação, conforme aponta a meta 16 do documento.

Configuram-se, pois, a partir do presente estudo, avanços mas também lacunas e áreas a serem mais bem desenvolvidas nas políticas educacionais, no horizonte da educação e da formação docente em perspectivas multiculturalmente orientadas. 


\section{Considerações finais}

O olhar multicultural trabalha com a valorização da diversidade cultural e o desafio a preconceitos, preconizando, em perspectivas mais recentes, sua articulação ao currículo escolar e de formação docente, de modo a não ser entendido apenas de forma apartada dos conteúdos ministrados em ambos os níveis educacionais e de formação. Outrossim, desenvolve, também, em suas visões mais críticas e pós- coloniais, a sensibilidade para o caráter híbrido da construção identitária, de modo a desafiar visões congeladoras e essencializadas das mesmas, que podem terminar por criar outros estereótipos na contramão do que se espera de uma perspectiva multicultural educacional.

$\mathrm{Na}$ análise de trechos do PNE, efetuada no presente artigo, observamos que há, por um lado, avanços no sentido de reconhecimento da pluralidade e da responsabilidade em assegurar sua presença e acesso à educação pública de qualidade, bem como em fomentar a formação docente inicial e continuada que reconheça e lide com a mesma. Entretanto, por outro lado, observamos que o foco dado a esta diversidade encontra- se nas preocupações com identidades coletivasespecíficas, tais como povos indígenas, quilombolase na educação do campo, tomados de forma homogeneizante e essencializada e tendendo a se concentrar em aspectos ligados à questão do acesso, 0 que, de certa forma, acaba por naturalizar a exclusão desses gruposminoritários, sem que se busque superar as condições que perpetuam as desigualdades e a exclusão, ou que se pense em currículos de formação de professores que questionem a construção dessas desiguladades e dessa exclusão.

Taistendências aparecem em váriasmetas do PNE, conforme discutido no presenteartigo, o que parece indicar a necessidade de que grupos e identidades sejam percebidos para além dasessencializações dosmarcadores de raça, etnia, gênero ou classe social. Enfatizamos, assim, a relevância de que planos e políticas educacionais possam focalizar as diferenças para além dessas perspectivas, de modo a não acabarem por mistificarem e promoverem a exclusão daquelas identidades que não se encaixem em modelos-padrão. Para tal, sugeríamos que sejam desessencializadas e problematizadas as questões de classe, etnia/raça e gênero, dentre outras; e que as discussões acerca dos grupos menos favorecidos sejam desnaturalizadas, oferecendo-se, ao mesmo tempo, perspectivas que articulem o pensamento curricular valorativo e potencializador de uma educação mais humana e menos excludente.

\section{Referências}

ASSIS, M. D. P.; CANEN, A. Identidade Negra e Espaço Educacional: histórias e contribuições do multiculturalismo. Cadernos de Pesquisa, v. 324, n. 123, Petrópolis, RJ : Vozes. set/dez 2004. p. 709-724

BRASIL. Lei $n-5.692$, de 11 de agosto de 1971. Fixa diretrizes e bases para 0 ensino de $1^{0}$ e $2^{\circ}$ graus, e dá outras providências. Diário Oficial [da] República Federativa do Brasil, Brasília, DF, 11 ago. 1971. 
BRASIL. Ministério da Educação. Projeto de Lei do Plano Nacional de Educação: PNE - 2011/2020. Brasília, DF: Câmara dos Deputados, Edições Câmara, 2011.

CANDAU, V. M.; ANHORN, C. T. G. A questão didática e a perspectiva multicultural: uma articulação necessária. In: CANDAU, V. M. (Org.). Sociedade: educação e cultura(s): questões e propostas. Petrópolis, RJ : Vozes, 2002.

CANDAU, V. M. Multiculturalismo e educação: desafios para prática pedagógica. In: MOREIRA, A. F.; CANDAU V. M. (Org.) Multiculturalismo: diferenças culturais e práticas pedagógicas. Petrópolis, RJ: Vozes, 2008.

- Pluralismo cultural, cotidiano escolar e formação de professores. In: CANDAU, V. M. (Org.) Magistério: construção cotidiana. Rio de J aneiro: Vozes, 1997.

. Didática: questões contemporâneas. Rio de Janeiro: Forma \& Ação, 2009.

CANEN, A. Sentidos e dilemas do multiculturalismo: desafios curriculares para o novo milênio. In: LOPES, A. C.; MACEDO, E. (Orgs.). Currículo: debates contemporâneos. São Paulo: Cortez, 2002. p. 174-195.

. 0 multiculturalismo e seus dilemas: implicações na educação. Comunicação ct Política, v. 25, n. 2, mai./ago. 2007.

A educação Brasileira e o currículo a partir de um olhar multicultural: Älgumas tendências e perspectivas. In: BARROS, José Flavio e OLIVEIRA, Luiz Fernandes (org.) Todas as cores na educação: contribuições para uma reeducação das relações étnico- raciais no ensino básico. Rio de Janeiro: Quartet, p. 59-79, 2008.

. Currículo, diversidade e formação docente. In: BARROS, R. M. de. (Org.) Subjetividades e educação: conexões contemporâneas. Rio de Janeiro: Contra Capa, 2009.

CANEN, A.; CANEN, A. Rompendo fronteiras curriculares: o multiculturalismo na educação e em outros campos do saber. Currículo Sem Fronteiras, v.5, n. 2, p. 40-49, jul/dez. 2005.

Multiculturalism and peace studies: the need of a dialogue in/for multicultural and peace education. In: INTERNATIONAL PEACE RESEARCH ASSOCIATION GLOBAL CONFERENCE, 23., 2008, Leuven. Trabalho apresentado ... Leuven, Bélgica: International Social Science Council, 2008.

CANEN, A.; SANTOS, A. R. Educação multicultural: teoria e prática para professores e gestores em educação. Rio de Janeiro: Ciência Moderna, 2009. 
CANEN, A.; XAVIER, G. P. de Moura. Multiculturalismo, pesquisa e formação de professores: 0 caso das diretrizes curriculares para a formação docente. Ensaio: aval. Pol. Publ. Educ., Rio de Janeiro, v. 13, n. 48, p. 333-344, jul./set. 2005.

CONFERÊNCIA NACIONAL DE EDUCAÇÃO (Brasil). Construindo o sistema nacional articulado de educação: o plano nacional de educação, diretrizes e estratégias de ação: documento referência. Brasília, DF, 2010. Disponível em: < http://portal.mec. gov.br/arquivos/pdf/conae/documento_referencia.pdf>. Acesso em: 08 out. 2012.

HALL, S. A Centralidade da cultura: notas sobre as revoluções culturais do nosso tempo. Educação e realidade, v. 22, n. 2, p.15-46, jul./dez. 1997.

KUENZER, A. Z. As políticas de formação: a constituição da identidade do professor sobrante. Educação e sociedade, Campinas, v. 20, n. 68, 1999. Disponível em: <http: //www.scielo. $\mathrm{br} / \mathrm{scielo}$.php?script=s0101-73301999000300012 \& ing = ptgnrm=isso>acesso em 30 agosto 2006 doi 10.1590/S010-7331999000300009>. Acesso em: 8 out. 2012.

MCLAREN, P. A Vida nas escolas: uma introdução à pedagogia crítica nos fundamentos educacionais. Porto Alegre: ArtMed, 1997.

- Multiculturalismo revolucionário: pedagogia do dissenso para o novo milênio. PortoAlegre: Artes Médicas, 2000.

MOREIRA A. F.; CANDAU V. M. Multiculturalismo: diferenças culturais e práticas pedagógicas. Petrópolis, RJ: Vozes, 2008.

OLIVEIRA, L. F. Histórias da África e dos africanos na escola: as perspectivas para a formação dos professores de história quando a diferença se torna obrigatoriedade curricular. 2010. Tese (Doutorado)-Departamento de Educação, Pontifícia Universidade Católica do Rio de Janeiro, Rio de Janeiro, 2010.

OLIVEIRA, L. F; CANDAU V. M. Pedagogia decolonial e educação antirracista e intercultural no Brasil. In: CANDAU, V. M. (Org.). Diferenças culturais e educação: construindo caminhos. Rio de Janeiro: 7 letras, 2011. p. 79-109.

SILVA, T. T. O Currículo com fetiche: a poética e a política do texto currículo. Belo Horizonte: Autêntica, 2001.

SISS, A. Educação, cidadania e multiculturalismo. In: REUNIÃO ANUAL DA ANPED, 26., 2003, Poços de Caldas. Trabalhos apresentados...M inas Gerais: DP\&A, 2003.

Recebido em: 02/04/2013

Aceito para publicação em: 01/07/2013 